\title{
NOCTURNAL BLOOD PRESSURE IS RELATED TO THE PROGRESSION OF RETINOPATHY IN TYPE 1 DIABETIC PATIENTS
}

FJ. Vilchez López ${ }^{1}$, I. Mateo Gavira ${ }^{1}$, L. Larrán Escandón ${ }^{1}$, A. Montero Galván ${ }^{1}$, J. Ortego Rojo ${ }^{1}$, MV García Palacios ${ }^{2}$, M. Aguilar Diosdadoํ.

1. Endocrinology, Puerta del Mar Hospital, Cádiz, Spain.

2. Preventive Medicine and Public Health, Cádiz, Spain.

\section{INTRODUCTION}

The main objective is to evaluate the relationship between early blood pressure alterations (detected by ambulatory blood pressure monitoring abpm-) and the development/progression of retinopathy in patients with type 1 diabetes clinically normotesive

\section{METHODS}

We designed a prospective observational study of 85 patients, clinically normotensive and without microalbuminuria, monitored over 7 years. Abpm was performed over $24 \mathrm{~h}$ and subclinical hypertension was considered if: 1) mean systolic pressure (sbp) was greater than $130 \mathrm{mmHg}$ in the 24 hours and daytime periods and greater than $120 \mathrm{mmHg}$ in the nighttime period and/or mean diastolic pressure (dbp) greater than $80 \mathrm{mmHg}$ or $70 \mathrm{mmHg}$ in the same periods respectively, and/or 2) more than $50 \%$ of the readings were higher than the defined previous criteria. Non dipper pattern was defined as nocturnal sbp or $\mathrm{dbp}<10 \%$ relative to the diurnal mean value. We evaluated the development or progression of retinopathy during the following period.

\section{RESULTS}

23.5\% ( $n=20)$ were diagnosed with subclinical hypertension and $36 \%(n=31)$ with non dipper pattern as the only pathological finding. 69 patients completed the seven-year follow-up. During this period, $31.8 \%$ presented development or progression of retinopathy. Initial mean nocturnal dbp (OR: 1.122, p: 0.034) and final non dipper pattern (or: 5.857, p: 0.005) showed as independent risk factors of progression/development of retinopathy.

Table 1. Characteristics of participants $(n=85)$ at the start of the study

\begin{tabular}{|l|c|}
\hline \multicolumn{2}{|c|}{ Anthropometric and demographic variables } \\
\hline Age (years) & $27,9 \pm 6,1$ \\
\hline Duration of DM1 (years) & $12,3 \pm 6.5$ \\
\hline Sex (no. of subjects and \%) & \\
Female & $47(55,3)$ \\
Male & $38(44,7)$ \\
\hline Body-mass index (Kg/m2) & $24,1 \pm 3,1$ \\
\hline Family history of hypertension (no. of subjects and \%) & $52(61,2)$ \\
\hline Family history of diabetes (no. of subjects and \%) & $63(74,1)$ \\
\hline Glycosylated hemoglobin (\%) & $7,9 \pm 1,1$ \\
\hline
\end{tabular}

Table 3. Multiple regression analysis of patients analyzed at 7 years of follow-up using retinopathy progression as dependent variable

\begin{tabular}{|l|c|c|c|}
\hline \multicolumn{1}{|c|}{ Variable } & OR & $95 \% \mathrm{Cl}$ & $\mathbf{p}$ \\
\hline $\begin{array}{l}\text { Initial dbp in repose } \\
\text { period }\end{array}$ & 1.122 & $1.01-1.25$ & 0.034 \\
\hline $\begin{array}{l}\text { Initial levels of } \\
\text { cholesterol }\end{array}$ & 1.023 & $1.00-1.05$ & 0.054 \\
\hline $\begin{array}{l}\text { Initial waist } \\
\text { circumference }\end{array}$ & 1.075 & $1.01-1.15$ & 0.028 \\
\hline $\begin{array}{l}\text { Final non-dipper } \\
\text { pattern }\end{array}$ & 5.857 & $1.68-20.39$ & 0.005 \\
\hline
\end{tabular}

Table 2. Baseline characteristics of subjects analyzed at 7 years of follow-up ( $n=69)$

\begin{tabular}{|c|c|c|}
\hline \multicolumn{3}{|c|}{ Baseline ambulatory blood pressure monitoring parameters } \\
\hline & \multicolumn{2}{|c|}{ Retinopathy progression } \\
\hline Parameters (mmHg) & $\begin{array}{r}\text { Normal or } \\
\text { estable }(n=47)\end{array}$ & $\begin{array}{r}\text { Progression } \\
(n=22)\end{array}$ \\
\hline 24-h systolic blood pressure mean & $118.2 \pm 8.8$ & $121.1 \pm 9.1$ \\
\hline Daytime systolic blood pressure mean & $121.8 \pm 9.2$ & $124.3 \pm 9.2$ \\
\hline Asleep systolic blood pressure mean & $107.7 \pm 10.2 *$ & $111.1 \pm 10.4 *$ \\
\hline 24-h diastolic blood pressure mean & $72.1 \pm 8.2$ & $75.1 \pm 10.4$ \\
\hline Daytime diastolic blood pressure mean & $74.4 \pm 5.9$ & $76.3 \pm 5.1$ \\
\hline Asleep diastolic blood pressure mean & $61.3 \pm 5.5 *$ & $64.8 \pm 7.3^{*}$ \\
\hline Non-dipper; $\mathrm{n}(\%)$ & $21(44.7 \%)$ & $11(50 \%)$ \\
\hline & & $* p<0.005$ \\
\hline
\end{tabular}

Figure 1. Percentage of progression of retinopathy as a function of diastolic blood pressure in repose period

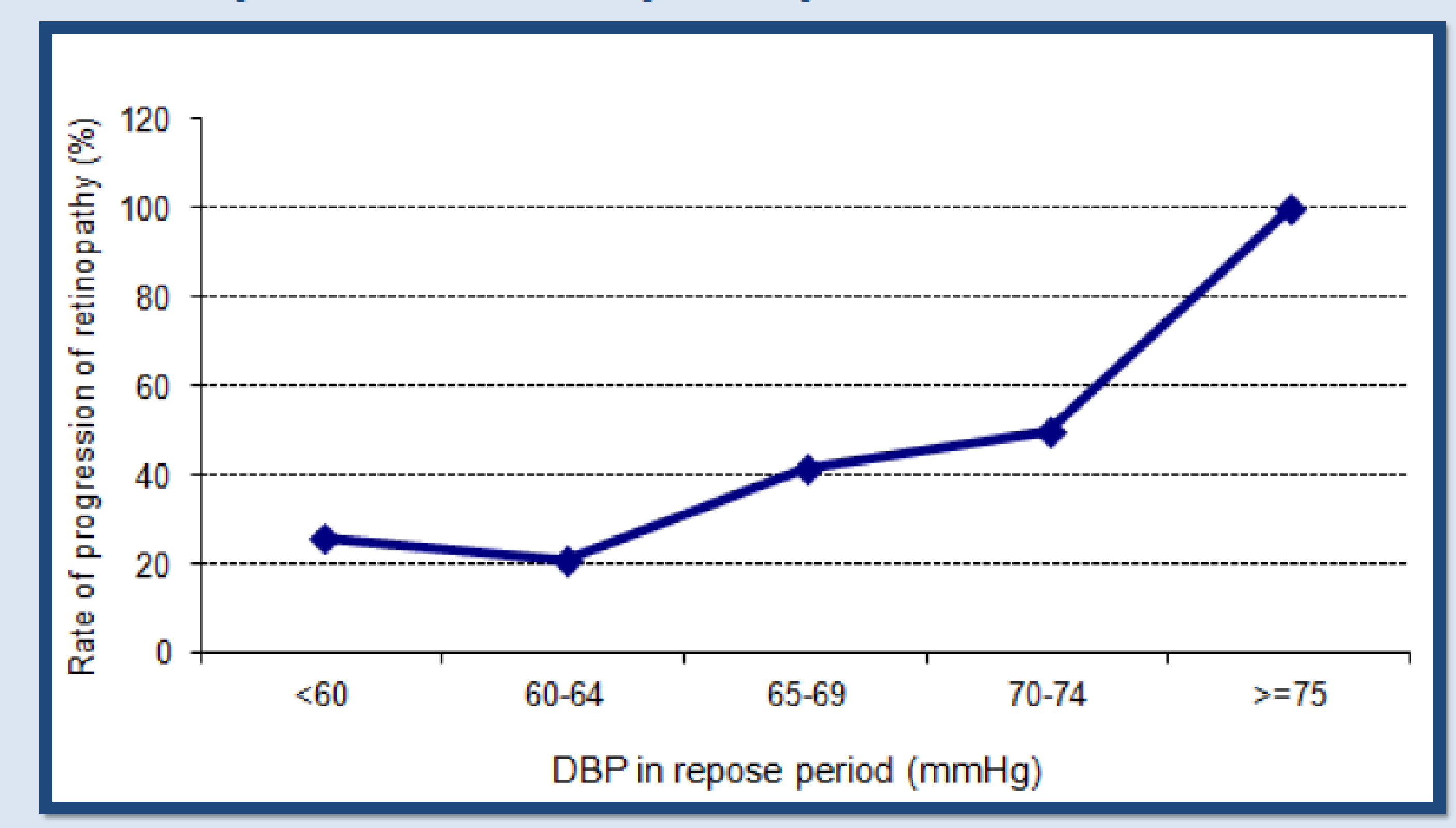

\section{CONCLUSIONS}

In type 1 diabetic patients clinically normotensive there is a high prevalence of blood pressure alterations detected by abpm. Nocturnal blood pressure parameters predisposes the development or progression of retinopathy. 